\title{
Avaliação de resultados e financiamento em organizações culturais não-empresariais
}

\section{Performance Evaluation and Sponshorship of Non Entrepreneurial Cultural Organizations}

\author{
Fabiula Meneguete Vides da Silva ${ }^{1}$ \\ Eloise Helena Livramento Dellagnelo²
}

\section{Resumo}

Diferentes aspectos relativos à gestão de organizações não empresariais vêm despertando o interesse de gestores e acadêmicos da área de estudos organizacionais. Uma destas questões que merece destaque consiste na busca por financiamento por parte destas organizações e as relações de poder estabelecidas neste processo. Assim, analisam-se neste trabalho os critérios de avaliação de desempenho utilizados por fontes financiadoras de grupos teatrais existentes em Florianópolis - SC. Foram analisadas seis fontes financiadoras: duas públicas, uma para-estatal e três organizações privadas. Investigou-se o processo de financiamento considerando os aspectos: captação dos projetos; exigências das propostas; avaliação das propostas e acompanhamento da execução dos projetos. Com base nos dados observou-se a presença de diversos critérios: qualificação pessoal, controle de despesas, registros internos, qualidade do espetáculo, impactos na sociedade. Critérios explorados pelo SESC despertam a curiosidade por estarem menos relacionados aos processos organizacionais internos, diminuindo possivelmente impactos na estruturação dos grupos em direção ao modelo burocrático.

Palavras-chaves: Avaliação de desempenho. Organizações civis sem fins lucrativos. Organizações sociais culturais. Grupo teatral. Fontes financiadoras.

\begin{abstract}
Many different issues related to non entrepreneurial organizations have been taken the attention of managers and academics concerned with organization studies. An important point of concern has been their search for financial support and power relationship established among different actors in such scenario. The objective of this work is to present and analyze the process that some theatrical scenic groups have been passing through in relation to different financial sponsors. Six financial sponsors were studied in this research: three public ones and three private organizations. The financing process was analyzed considering aspects such as: announcing mechanisms to attract projects, demanding aspects for an approval, the evaluation criteria applied when analyzing the proposals. According to the results different effectiveness criteria were observed in the process such as personnel qualification, internal controls, registers and documentation, quality of the show and impact on the general public or society. Criterion explored by a non-profit civil organization seemed less related to internal organizational processes, thus decreasing possible impacts on the bureaucratization of the cultural organizations.
\end{abstract}

Key Words: Performance evaluation, performance evaluation models, non-profit civil organizations, cultural social organizations, scenic groups, financial support.

\footnotetext{
${ }^{1}$ Professora na Universidade do Planalto Catarinense. Doutoranda no Programa de Pós-Graduação em Engenharia de Produção da Universidade Federal de Santa Catarina e mestre em Administração pela Universidade Federal de Santa Catarina. Endereço: Rua Presidente Roosevelt, 306-Copacabana - LAGES/Santa Catarina - Brasil - CEP: 88504020. E-mail: fabiulamv@yahoo.com.br

${ }^{2}$ Professora na Universidade Federal de Santa Catarina - UFSC.Doutora em Engenharia da Produção pela Universidade Federal de Santa Catarina. Endereço: Universidade Federal de Santa Catarina, Centro Sócio-Econômico, Departamento de Ciências da Administração. Campus Universitário Trindade - Florianópolis/ Santa Catarina - Brasil - CEP: 88040-900 - E-mail: eloise@ cse.ufsc.br
} 


\section{Considerações iniciais}

Diversas são as discussões no campo da administração acerca das novas formas organizacionais; ou seja, sobre as organizações que de alguma forma apresentam forma distinta do modelo burocrático. Segundo Dellagnelo (2000), por exemplo, o ambiente recente, caracterizado por intensa competição, vem sendo identificado pela maioria dos autores como fator determinante das novas abordagens organizacionais, principalmente, em relação à flexibilização em organizações empresariais.

Não obstante a importância desse universo de estudo, acredita-se que no campo das organizações sem fins lucrativos pode-se obter evidências mais significativas de práticas de gestão que signifiquem maior distanciamento do modelo organizacional tradicional. Entretanto, debates recentes nesse campo vem salientando a necessidade de profissionalização dessas organizações, argumentando a respeito da adoção de práticas gerenciais cada vez mais próximas dos modelos empresariais.

A princípio, acredita-se que as organizações civis sem fins lucrativos possam ser exemplos de formas organizacionais alternativas ao modelo burocrático, já que são organizações onde não se aplica predominantemente a lógica econômica empresarial, ou seja, a otimização de resultados e a maximização de recursos. No entanto, conforme esclarece Andion (1998), pode-se identificar nos estudos organizacionais uma forma de pensamento a respeito dessas organizações baseada na visão funcionalista, a qual está apoiada em concepções teleológicas, a-históricas, integrativas, sistêmicas e não conflituais.

Salienta-se que o aumento significativo do número dessas organizações tem provocado um incremento considerável na demanda por recursos financeiros. Esses recursos podem ser provenientes tanto de organizações públicas quanto de organizações privadas, fundações e da comercialização de seus próprios produtos e serviços. Hudson (1999) afirma que as fontes financiadoras tornam-se atores cada vez mais importantes na dinâmica desse setor, exercendo uma influência que pode ser ao mesmo tempo positiva e negativa. Do lado positivo, o autor salienta a ajuda dos financiadores em forçar os provedores a se concentrarem na realização de seus objetivos. "No lado negativo, os financiadores podem seduzir as entidades, no sentido de aceitar dinheiro que desvia a organização de seu propósito principal" (HUDSON, 1999, p.276). Conforme Monte e Carvalho (2004, p.1), "assim nasceram as denominadas parcerias, que, protegidas pela conotação de harmonia do termo, encerram relações de poder que interferem no curso da ação das organizações envolvidas".

Cruz (1998, p.1) sugere a reflexão sobre os tipos de fontes de financiamento que não conflitam com a missão da instituição financiada. "Não alterar ou não desviar sua missão, ação, política e programa pelo fato das organizações receberem doação de alguma fonte em especial, consiste num princípio fundamental na captação de recursos." Para o autor, "a missão de uma entidade sem fins lucrativos está além dos desejos de um potencial financiador."

No universo das organizações civis sem fins lucrativos estão incluídas as organizações com objetivos culturais, as quais vem crescendo no país, tanto em número, quanto em tamanho. Segundo Hudson (1999), a contribuição principal das organizações com objetivos culturais está na capacidade de, em sua especificidade, representarem o pensamento das pessoas, inovando e proporcionando um sentido de cidadania. Goulart, Menezes e Gonçalves (2003) reforçam essa idéia, argumentando que a vitalidade das organizações culturais denota aspectos importantes de nossa vida social.

Diferentes autores afirmam que o setor cultural começa a se beneficiar da importância que as empresas privadas e públicas vêm dando à associação de seus nomes a ações e projetos considerados de grande relevância pela sociedade, o que tem ampliado consideravelmente as alternativas de financiamento para esse tipo de organização. Conforme afirma Szazi (2004), percebe-se cada vez mais claramente que a ação social nos dias atuais não é mais aquela baseada na caridade e na atuação descompromissada com os destinos dos assistidos. Hoje, as ações sociais - tanto dos indivíduos, como das empresas - têm sido amparadas no conceito de 
responsabilidade social, segundo o qual o doador não é mais considerado um mero espectador, pois ele passa a ser um ator social que exerce uma função mais decisiva. Dessa perspectiva, "surgiram novas expectativas sobre a atuação da entidade receptora" (SZAZI, 2004, p.1). A doação chamada de descompromissada foi substituída, segundo Szazi, pela doação engajada, pautada por práticas consideradas por ele éticas e focadas em resultados do investidor social. Conforme esclarecem Reis e Santos (1996), o mecenato moderno deixa de ser uma forma de colaboração desinteressada por parte das empresas, assumindo efetivamente um compromisso com a estratégia empresarial.

Quanto aos critérios de avaliação utilizados por esses financiadores, no entanto, trata-se de um tema ainda pouco claro na área organizacional. A literatura a respeito da avaliação de desempenho organizacional concentra-se fundamentalmente em discussões voltadas ao campo empresarial.

Considerando o poder das fontes financiadoras na dinâmica das organizações culturais, objetivou-se neste artigo estudar os critérios de avaliação de desempenho utilizados por seis fontes financiadoras de grupos teatrais de Florianópolis-SC. Com base em levantamento prévio, foram identificadas seis importantes organizações nesse processo: a Fundação Catarinense de Cultura (FCC), vinculada ao governo do estado; a Fundação Cultural de Florianópolis - Franklin Cascaes (FCFFK), vinculada à administração municipal; a Brasil Telecom S.A./SC; o Serviço Social do Comércio (Sesc) de Santa Catarina; Eugênio Raulino Koerich S.A. Comércio e Indústria (Lojas Koerich) e o grupo Orcali.

\section{Fontes financiadoras de ações sociais}

Vários são os autores que vêm enfatizando a gestão de resultados em organizações sem fins lucrativos. Para Santos (1999), por exemplo, o principal desafio que as organizações civis sem fins lucrativos enfrentam diz respeito tanto a sua gestão quanto à geração de resultados que possibilitem sua perenidade, aperfeiçoamento e crescimento. Segundo Rossi Júnior (2001), apesar dessas organizações não terem o lucro como objetivo e tenderem a não dar prioridade ao desempenho e aos resultados, aspectos difíceis de medir e controlar, elas sofrem a crescente pressão por desempenho e prestação de contas, principalmente, por parte dos agentes financiadores. Sabe-se, contudo, que essa exigência

[...] pode trazer uma mudança profunda no perfil dessas organizações, que de organizações flexiveis, altamente adaptáveis e movidas por ideologias, podem se transformar em organizações altamente burocratizadas e com estrutura rígida, talvez até "filiais" de grandes empresas ou governos nacionais, perdendo as características que as tornam únicas. (SILVA; SILVA, 2002, p.1)

Os recursos necessários para a manutenção das atividades das organizações pertencentes a esse setor podem ser originários de fontes nacionais ou internacionais, advindos de instituições privadas ou governamentais (LANDIM, 1999 apud CRUZ; ESTRAVIZ, 2000). A relação entre as fontes financiadoras e as organizações civis sem fins lucrativos vem se alterando, principalmente, na última década. Segundo Hudson (1999), durante muitos anos, o governo e as organizações privadas viam-se como doadores e tinham pouco interesse em se envolver com essas organizações, uma vez que tinham recebido em troca a publicidade esperada. Atualmente, os financiadores estão ávidos por retornos maiores e toda e qualquer relação com as organizações civis sem fins lucrativos dá-se através de contratos aprovados após apresentação de propostas (HUDSON, 1999).

Conforme Silva e Silva (2002), pode-se observar indicadores de alta burocratização nas organizações civis sem fins lucrativos que são financiadas por outras organizações, ao contrário daquelas que contam com financiamento de pessoas físicas. Para os autores, as organizações civis sem fins lucrativos estão absorvendo uma cultura burocratizada e corporativa. Esse processo de enrijecimento e empresarização (SOLÈ, 2004) pode muitas vezes significar o distanciamento dos seus objetivos iniciais, conforme salientam Hoffmann e Dellagnelo (2006). 
Argumenta-se, com base em Montaño (2003), que há de se estudar e analisar os reflexos dos agentes financiadores na gestão das organizações civis sem fins lucrativos, uma vez que a captação de recursos "tornase não apenas uma atividade essencial da organização, mas [que] ainda pode passar a orientar a filosofia e a condicionar a sua missão"(Ibidem, p.20). Conforme salienta o autor, a ênfase na captação de recursos, pode levar a organização a uma perda de identidade e de rumo, descaracterizando, dessa forma, seu papel na sociedade.

\section{Modelos de desempenho organizacional}

O desenvolvimento dos estudos sobre desempenho ficou condicionado, segundo vários autores, a distintas e concorrentes abordagens, tornando assim sua compreensão ainda mais complexa e polêmica na literatura organizacional. O desempenho de uma organização pode ser entendido como sua capacidade de alcançar determinados resultados ou de ser considerada uma organização de sucesso. Na medida em que as possibilidades na determinação dos objetivos organizacionais (PERROW, 1961), são múltiplas, bem como na determinação do que seja sucesso, diferentes abordagens sobre desempenho organizacional são encontradas na literatura.

Alguns autores diferenciam os significados de eficiência, eficácia e efetividade organizacional, a exemplo de Tripodi et al (1975 apud FRASSON, 2001), o qual entende que os sistemas de avaliação que não contemplem esses três critérios são considerados incompletos, na medida em que esses indicadores de desempenho estão inter-relacionados. Woley et al (1994 apud FRASSON, 2001, p.74) defendem

que um projeto de avaliação deve incluir formas de descrever os recursos do programa (eficiência), os resultados do programa (eficácia) e os métodos para calcular os impactos líquidos das atividades do programa (efetividade).

Dellagnelo (1997), em seu estudo de caso sobre modelos de desempenho e postura estratégica, resumiu as diversas tentativas de integrar a literatura acerca da eficácia organizacional, conforme se pode observar no quadro 1 .

Quadro 1

Principais modelos de eficácia

\begin{tabular}{ll}
\hline Autor & Modelos de Eficácia Organizacional \\
\hline Campbell & Centrados nos objetivos/de sistema natural \\
\hline Miles & De alcance de objetivos/de sistemas/“ecológico" \\
\hline Coulter & De alcance de objetivos/processual/atitudinal-comportamental \\
\hline Scott & De sistema racional/de sistema natural/de sistema aberto \\
\hline Seashore & De objetivos/de sistema natural/de processo decisório \\
\hline Cameron & De objetivos/recursos de sistema/de processos internos/de satisfação dos participantes \\
\hline
\end{tabular}

Fonte: Dellagnelo (1997).

Quinn e Rohrbaugh (1983 apud QUINN; CAMERON, 1983) resumem esses principais modelos de eficácia em quatro blocos, considerando dois importantes eixos: flexibilidade e controle e foco interno e externo. Os quatro principais modelos de eficácia identificados que contemplam uma gama significativa de indicadores de resultado de uma organização são: modelo de relações humanas, modelo de processos internos, modelo de sistemas abertos e modelo de metas.

O primeiro modelo, mais citado na literatura, é o modelo de objetivos, também denominado modelo racional de metas, modelo de sistema racional ou modelo de metas. $\mathrm{O}$ primeiro modelo, mais citado 
na literatura, é o modelo de metas, também denominado modelo racional de metas, modelo de sistema racional ou modelo de objetivos. Hall (2004) afirma que esse modelo de eficácia é caracterizado por ser ao mesmo tempo simples e complexo. Também é o mais utilizado e o mais antigo na avaliação de eficácia organizacional (BOWDITCH; BUONO, 1992; CAMERON, 1978; DEELEY, 1984 apud DELLAGNELO; DELLAGNELO, 1996).

Os autores que descrevem os modelos de avaliação baseados em objetivos ou metas racionais tendem a enfatizar o atendimento a metas financeiras. Nesse sentido, Pace et al (2004) acreditam existirem limitações no modelo, em relação aos sistemas de mensuração financeira como forma de avaliar o sucesso ou o fracasso dos administradores. acreditam que o modelo apresenta limitações, no que diz respeito aos sistemas de mensuração financeira como forma de se avaliar o sucesso ou o fracasso dos administradores. Conforme os autores, esses fatores indicam o desempenho após a ocorrência dos fatos; ou seja, são indicadores de ocorrência da criação de valor, sem foco na capacidade de criar valor futuro.

O chamado modelo de sistemas abertos foi desenvolvido por Yuchtman e Seashore (1967) para suprir as falhas apresentadas no modelo de objetivos. Os autores entendem que a eficácia de uma organização é determinada por sua capacidade de explorar seu ambiente, a fim de adquirir recursos escassos e valorizados para manter seu funcionamento. Dessa perspectiva, deve ser considerada a importância de se utilizar o ambiente de maneira racional, já que se as organizações o utilizarem de maneira predatória, poderá ocorrer uma escassez total de recursos. Segundo Dellagnelo e Dellagnelo (1996), de acordo com o modelo de sistemas abertos, uma organização é considerada eficaz na medida em que maximiza sua posição de barganha no ambiente e otimiza a obtenção de recursos.

O terceiro modelo, o de recursos humanos, - também chamado modelo de satisfação dos participantes, modelo de relações humanas ou modelo de constituições estratégicas - fundamenta-se no argumento de que a eficácia organizacional é definida através de características comportamentais. Assim, critérios de satisfação, comprometimento e moral dos empregados seriam preponderantes no estabelecimento da eficácia organizacional (COULTER, 1979). De acordo com esse modelo, fatores como lucratividade e produtividade são condições essenciais para a subsistência da organização e não fins em si mesmos. Assim, as organizações mais eficazes são aquelas em que os funcionários aderem e concordam com as metas da organização, trabalhando dessa forma, sistematicamente, para alcançá-las.

O quarto modelo apresentado é o modelo de processos internos, também chamado de modelo de operações e processos internos. Segundo Cameron (1978), nesse modelo a eficácia é verificada nos processos internos de aquisição e utilização de recursos, em vez de ser verificada em um estado final. O modelo em questão tem seu foco na dinâmica interna da organização. Desse modo, a utilização dos recursos e o bom relacionamento entre os membros da organização são considerados indicadores importantes de uma organização eficaz. Pode-se citar como exemplos de critérios de eficácia, segundo Bowditch e Buono (1992, p.192), "ausência de tensões internas, boa integração dos seus membros, elevado nível de confiança entre os integrantes da organização e benevolência para com eles, fluxo regular de informações vertical e horizontalmente [...]".

De acordo com Hall (2004), além dos quatro modelos já citados, ainda pode-se encontrar na literatura o modelo de função social, focado no que fazem as organizações com ou para a sociedade onde estão inseridas.

Para Aktouf (1996), a avaliação de desempenho das organizações deveria primar pela observação da rentabilidade das atividades econômicas, mas a busca por essa rentabilidade não deveria acontecer a qualquer preço. Devido à importância que as organizações representam na vida do homem, não se deve, ainda segundo Aktouf (1996, p.228), deixar de refletir a respeito do lugar que elas ocupam e do papel que desempenham em todos os aspectos da vida. Assim, para o autor, faz-se necessária uma reflexão a respeito do tratamento dispensado pelas organizações ao meio ambiente, aos empregados e aos parceiros menos privilegiados. 
A reflexão trazida por Aktouf tende à integração dos quatro modelos citados anteriormente, tendo em vista que não somente a rentabilidade típica do modelo de objetivos é importante, mas também outros critérios, tais como o desenvolvimento pessoal dos funcionários (modelo de recursos humanos), que deve ser considerado relevante no processo de avaliação de desempenho.

Herman e Renz (1998) discutem a avaliação de desempenho em organizações sem fins lucrativos e entendem que essa questão continua a deixar pesquisadores desgostosos. Uma organização civil sem fins lucrativos que aumenta seu rendimento rapidamente é mais eficaz do que outra que apresente déficit? Uma organização civil sem fins lucrativos com baixas despesas é mais eficaz do que outra com despesas moderadas? Muitos argumentam que aquilo que determina a eficácia organizacional nesse tipo de organização é o alcance de sua missão. No entanto, avaliar a realização da missão em uma organização não é tarefa fácil. Assim, comparar a extensão da realização da missão em diferentes tipos de organizações sem fins lucrativos tende a ser tarefa ainda mais difícil.

Dempsey et al (1997) apontam que a facilidade de acesso às medidas não-financeiras já é limitada no setor privado, principalmente, quando se trata de medidas de satisfação do público-alvo e de qualidade dos serviços e produtos. Nas organizações civis sem fins lucrativos, essa situação é agravada, pois envolve, segundo Fischer (1996 apud Pace et al, 2004), características pouco conhecidas, tais como, a importância do trabalho voluntário e militante, o uso de trocas em espécie e favores e o efeito multiplicador da solidariedade; aspectos que, muitas vezes, são capazes de explicar o sucesso de empreendimentos sociais.

Segundo Pace et al (2004, p. 3), pode-se entender que "seja no setor privado, seja no terceiro setor, as medidas qualitativas, quando abertas ao público, apresentam-se insuficientes, dada sua extrema diversidade e ausência de um padrão único para divulgação". Para esses autores, o estudo da eficácia organizacional é especialmente problemático no contexto das organizações civis sem fins lucrativos. Primeiro de tudo, porque sua situação financeira e sua situação legal diferem do verificado nas organizações pertencentes ao primeiro e segundo setor. Em segundo lugar, as medidas quantitativas comumente utilizadas para avaliar as organizações privadas são freqüentemente difíceis de serem utilizadas em organizações sem fins lucrativos, porque estas normalmente possuem metas qualitativas, de difícil mensuração. Finalmente, o trabalho de organizações civis sem fins lucrativos é baseado em valores sociais sobre os quais há pouco ou nenhum consenso. A área social não dispõe de um acúmulo teórico sobre a sua gestão e necessita de respostas específicas que possam diferir das procuradas pelo campo empresarial.

\section{Procedimentos metodológicos da pesquisa}

Esta pesquisa caracteriza-se como qualitativa do tipo estudo de casos múltiplos. É um estudo descritivo com perspectiva longitudinal. Caracterizam-se como seu universo seis fontes financiadoras de grupos teatrais nãoempresariais de Florianópolis-SC. Após levantamento realizado em 33 grupos teatrais existentes na cidade, escolheu-se estudar aquelas fontes financiadoras mais citadas pelos próprios entrevistados, que são: a Fundação Catarinense de Cultura (FCC), a Fundação Cultural de Florianópolis - Franklin Cascaes, a Brasil Telecom S.A./SC, o Serviço Social do Comércio de Santa Catarina (Sesc-SC), a Eugênio Raulino Koerich S.A. Comércio e Indústria (Lojas Koerich) e o Grupo Orcali.

As fontes de financiamento foram analisadas considerando-se os seguintes aspectos: captação de projetos (publicação formal ou não, canais utilizados, tempo, exigência pré-qualificatória aos interessados); exigências das propostas (documentos exigidos/forma de apresentação, qualificação dos profissionais, estrutura de apoio/contrapartida da organização, tipo de objetivos, prazo de cumprimento, volume dos recursos, resultados esperados); avaliação das propostas (pessoas envolvidas e critérios ponderados) e acompanhamento dos projetos (no processo $x$ no final, pessoal envolvido e divulgação de trabalhos/resultados).

Já os modelos de avaliação de desempenho foram analisados conforme os indicadores apresentados no quadro 2 
Quadro 2

Definição operacional dos modelos de avaliação de desempenho

\begin{tabular}{|c|c|}
\hline Modelos De Avaliação de Desempenho & Indicadores de Resultado \\
\hline \multirow{6}{*}{ Modelo de objetivos } & Objetivos quantificáveis \\
\hline & Custo dos serviços \\
\hline & Receitas \\
\hline & Despesas \\
\hline & Padrões de qualidade \\
\hline & Número de produtos/serviços oferecidos \\
\hline \multirow{6}{*}{ Modelo de sistema aberto } & Aquisição de recursos \\
\hline & Parcerias com outras organizações \\
\hline & $\begin{array}{l}\text { Divulgação dos produtos/serviços oferecidos pela } \\
\text { organização da sociedade civil sem fins lucrativos às } \\
\text { comunidades e órgãos financiadores }\end{array}$ \\
\hline & Relações sociais e de poder \\
\hline & Preocupação com o impacto social e ambiental \\
\hline & Satisfação do cliente externo \\
\hline \multirow{3}{*}{ Modelo das relações humanas } & $\begin{array}{l}\text { Desenvolvimento/treinamento/qualificação da força de } \\
\text { trabalho }\end{array}$ \\
\hline & Coesão entre os membros da organização \\
\hline & Satisfação das necessidades dos indivíduos \\
\hline \multirow{5}{*}{ Modelo do processo interno } & Comunicação vertical e horizontal \\
\hline & Previsibilidade \\
\hline & Controle \\
\hline & Informações \\
\hline & Planejamento intensivo \\
\hline
\end{tabular}

Fonte: as autoras.

A coleta de dados foi realizada por meio de entrevistas semi-estruturadas, aplicadas junto a informantes-chave em cada organização financiadora, e da análise de documentos, tais como atas de reuniões, relatório de 
atividades, relatórios anuais da administração, cópias do Diário Oficial do estado, projetos culturais e pareceres desses projetos.

Os dados primários foram analisados por meio da técnica de análise categorial, própria da análise de conteúdo citada por Bardin (2004). Após a transcrição das entrevistas, foram analisados os depoimentos, conforme as categorias de análise definidas. Esse procedimento foi realizado em todas as 14 entrevistas realizadas, permitindo ao pesquisador reunir as informações para posteriormente interpretá-las. No tratamento dos dados secundários foram utilizadas a análise documental e também de conteúdo.

\section{Análise das propostas dos grupos teatrais por parte dos financiadores}

Para que se entenda o processo de financiamento dos grupos de teatro, faz-se necessário, antes de tudo, o esclarecimento sobre as fontes de financiamento em análise

A Fundação Catarinense de Cultura (FCC) foi instituída por decreto em abril de 1979. Uma das formas mais expressivas de apoio aos projetos culturais adotada pela FCC é por meio da Lei no $10.929 / 98$, que institui o Sistema Estadual de Incentivo à Cultura (Seic), com o objetivo de estimular o financiamento de projetos culturais, especialmente, por meio da renúncia fiscal estadual referente ao Imposto sobre Operações Relativas à Circulação de Mercadoria e sobre prestação de Serviços de Transporte Interestadual e Intermunicipal e de Comunicação - ICMS. O órgão da FCC responsável pela gestão de projetos culturais intitula-se Executiva de Apoio à Cultura (Exac), onde trabalham seis funcionários responsáveis pela gestão do Seic, juntamente com o Conselho Estadual de Cultura (CEC), composto por 11 câmaras setoriais, a exemplo da Câmara de Artes Cênicas, de Música, de Cinema e Vídeo.

A segunda fonte financiadora analisada é a Fundação Cultural de Florianópolis - Franklin Cascaes (FCFFK), criada por lei municipal em junho de 1987. A Lei de Incentivo à Cultura Municipal (Lei no 3.659) estabelece que a Câmara Municipal de Florianópolis fixe anualmente na Lei Orçamentária o valor que deverá ser utilizado como incentivo cultural. A FCFFK sedia a Comissão Permanente de Cultura (CPC), que coordena o trâmite de projetos candidatos aos benefícios da Lei Municipal de Incentivo à Cultura. Essa comissão é um órgão independente e autônomo, formado majoritariamente por representantes do setor cultural e por técnicos da administração municipal, que ficam incumbidos da averiguação e da avaliação dos projetos culturais apresentados.

A Brasil Telecom S.A., fonte financiadora pertencente ao setor privado, surge a partir da cisão do Sistema Telefônico Telebras, ocorrida no primeiro semestre de 1998. A empresa já vinha financiando projetos sociais, culturais e esportivos, mesmo antes da cisão, por meio de sua configuração jurídica anterior (Telecomunicações do Estado de Santa Catarina). Na filial de Santa Catarina, o setor responsável pelos patrocínios é o de relações com a mídia e projetos, que responde diretamente à vice-presidência de relações externas, em Brasília. O setor de relações com a mídia e projetos conta com dois funcionários, um dos quais é diretamente responsável pelo apoio a projetos sociais, culturais e esportivos.

O Serviço Social do Comércio (Sesc) é uma instituição de âmbito nacional, sem fins lucrativos, criada em 1946 por iniciativa do empresariado, e que apresenta como seu principal objetivo a prestação de serviços sociais, com vistas à melhoria da qualidade de vida dos trabalhadores do comércio e serviços e de seus dependentes. Em Santa Catarina, o Sesc foi instalado em 1948. Segundo os entrevistados, a partir de 2000, o Sesc vem atuando mais fortemente e de forma mais planejada no campo da cultura. O Sesc possui alguns projetos voltados para o teatro, dos quais pode-se citar os mais relevantes: o Emcenacatarina - Circuito Catarinense Sesc de Teatro e Dança e o Palco Giratório - Circuito Nacional Sesc de Teatro e Dança. No campo da cultura, o Sesc atua através da divisão de programação social. Em Florianópolis, são dois funcionários responsáveis pelo programa cultural do Sesc no estado, trabalhando na forma de parceria entre as atividades voltadas à literatura, às artes plásticas e ao cinema e os projetos de teatro e música. 
A quinta fonte financiadora tem o nome de fantasia Lojas Koerich. É uma empresa privada especializada na venda de móveis e eletrodomésticos, com 49 lojas no estado e aproximadamente mil funcionários. A empresa tem apoiado projetos tanto na área social quanto nas áreas esportiva e cultural. Todas as ações nesta área são realizadas de maneira predominantemente informal, sem um planejamento prévio. A área responsável pelo apoio aos projetos é a de gerência de marketing, diretamente vinculada à direção da empresa. Os proponentes de projetos podem remeter suas propostas a qualquer ponto de venda da empresa situado no estado de Santa Catarina ou diretamente à direção da empresa.

O último financiador pesquisado é o grupo Orcali, empresa criada em 1968 com o objetivo de atender a um edital de serviços de limpeza publicado por uma organização pública de Florianópolis. Esse grupo conta com aproximadamente 2.500 funcionários distribuídos por todo o estado de Santa Catarina, desenvolvendo atividades de vigilância, segurança eletrônica, limpeza, serviços administrativos, de motorista, recepção, digitação, serviços gerais e de zeladoria. Diversos são os projetos sociais, culturais e esportivos apoiados pelo Orcali, embora não haja uma verba preestabelecida para essa atividade. Na empresa, o apoio a projetos culturais pode se dar de três formas: por meio do repasse de recursos financeiros sem a utilização da Lei de Incentivo à Cultura, por meio do repasse de recursos financeiros com utilização da Lei de Incentivo à Cultura e também com a cessão de funcionários para prestação dos mais diversos serviços oferecidos pela empresa nos eventos culturais. A área responsável tanto pelo recebimento quanto pela análise dessas propostas culturais é a de assessoria de marketing. Na medida em que os projetos chegam à assessoria, vão sendo analisados. Essa análise, geralmente, ocorre semanalmente numa reunião da qual participa um dos diretores da empresa.

A análise do processo de financiamento nesta pesquisa foi realizada levando-se em consideração a forma de captação de projetos, as exigências nas propostas, a avaliação dessas propostas e o processo de acompanhamento dos projetos.

\section{Captação de projetos}

A análise da captação de projetos buscou identificar a forma como acontece a divulgação do financiamento (quando ocorre) e os aspectos considerados previamente à apresentação da proposta.

Foi observado que a FCC e a FCFFK publicam editais em jornais impressos e na mídia em geral, o que caracteriza uma preocupação em ter uma divulgação ampla de suas possibilidades de financiamento. Pode-se supor que para essas organizações, um grupo teatral eficaz é aquele que dispõe de mecanismos de controle para monitorar os meios de comunicação em busca de informações sobre o apoio à consecução de seus projetos. Aqueles que não dispõem desses meios, certamente, tendem a ser desfavorecidos no processo.

Além de publicar editais, a FCC também se preocupa em oferecer cursos de capacitação sobre a Lei Estadual de Incentivo à Cultura (Leic), destinados aos produtores culturais do estado. Observa-se aqui a preocupação com a qualificação profissional dos sujeitos envolvidos no processo de financiamento, um critério associado ao modelo de recursos humanos. Dessa perspectiva, acredita-se que o melhor desempenho do grupo teatral também esteja associado a sua capacitação a respeito da Leic.

As outras quatro organizações: Brasil Telecom, Sesc-SC, Lojas Koerich e Orcali não fazem qualquer tipo de divulgação pública da captação dos projetos. São contatos pessoais diretos entre o financiador e grupo teatral que pode viabilizar a entrega de uma solicitação de financiamento. Nessa situação, parece estar presente o modelo de sistema aberto, já que o grupo teatral eficaz tende a ser aquele capaz de maximizar sua posição de barganha no ambiente externo no qual estão inseridos grupos teatrais e financiadores. Acredita-se que essa posição de barganha possa ser conseguida através das relações sociais (amizade, relações de parentesco e contatos prévios, por exemplo) do produtor teatral com membros da organização e/ou com outros grupos teatrais, para a troca de informações a respeito de quais são os financiadores de projetos culturais, ou através da 
divulgação do trabalho do grupo teatral, para que possa ocorrer um convite, como, por exemplo, é o caso do Sesc-SC.

É importante salientar que a Brasil Telecom e o Sesc, no passado, publicavam editais de apoio à cultura em jornais e na mídia em geral, para a chamada de produtores culturais. Assim, observa-se que elementos de eficácia próprios do modelo de processos internos estiveram presentes na fase inicial de captação de recursos, em alguns casos, já que o grupo teatral precisava estar monitorando os meios de comunicação e dispondo de mecanismos de controle para detectar informações importantes. Tal inferência justifica-se porque, para Cameron (1978), a eficácia nesse modelo é verificada através dos processos internos de aquisição de recursos, por meio da comunicação e da disponibilização de informações.

\section{Exigências das propostas}

A análise dos dados revelou que a maioria das organizações pesquisadas - o Sesc é uma das exceções - exige a inclusão na proposta do orçamento previsto para a realização dos projetos culturais. Nesse sentido, o grupo teatral deve apresentar informações sobre todos os custos necessários para a viabilização do seu projeto, tais como despesas com transporte, hospedagem, alimentação, figurino e cachê dos artistas. A exigência de informações a respeito dos custos dos projetos com antecedência pode ser caracterizada como a presença de critérios relacionados ao modelo de objetivos. Para Pace et al (2004), esse modelo está direcionado ao atendimento de metas financeiras e, para tanto, dados das receitas e despesas se caracterizam como importantes critérios de avaliação de desempenho organizacional.

De outra perspectiva, pôde-se perceber, também, a influência de indicadores do modelo de objetivos no processo de análise da Brasil Telecom, do Sesc-SC e do grupo Orcali. Nessas organizações, é importante a explicitação dos objetivos do grupo teatral na apresentação de seus projetos; ou seja, o grupo deve argumentar a respeito de sua preocupação com o desenvolvimento cultural da platéia ou de seus próprios membros. A falta de clareza quanto a esse aspecto pode inviabilizar uma análise mais detalhada dos projetos do grupo.

Os critérios relacionados aos processos internos estão também presentes na análise dos dados relativos ao financiamento na FCC, na FCFFK, na Brasil Telecom e no Sesc-SC. Todos exigem a apresentação de diferentes documentos e informações prévias a respeito do grupo teatral em suas propostas. Para a FCC e para a FCFFK o grupo teatral necessita preencher diversos formulários para a apresentação de sua proposta. Nesses formulários, deve ser informado, por exemplo, o número de inscrição do grupo no Cadastro Geral de Contribuintes (CGC) e o número do registro de identidade do Cadastro de Pessoas Físicas (CPF) do representante legal do grupo. Esse aspecto tem relação com o modelo de processos internos encontrado na literatura. Segundo Bowditch e Buono (1992), indicadores de desempenho próprios desse modelo revelam uma preocupação com o controle, com o foco interno da organização e com o fluxo regular de informações, operacionalizando-se, por exemplo, pela disponibilização de dados e documentos exigidos na apresentação da proposta.

O currículo do grupo teatral é considerado aspecto importante no momento da apresentação da proposta cultural para a FCC (a partir de 2001), para a FCFFK, para o Sesc-SC e para os avaliadores das Lojas Koerich. Aspectos como qualificação dos componentes e o histórico de outras produções culturais da equipe são critérios de análise relevantes.

A execução dos projetos que obtêm apoio deve contemplar a divulgação do nome das organizações financiadoras, especificamente, no caso da FCC, da FCFFK e do grupo Orcali. Essas organizações fazem questão, já no momento da apresentação da proposta, de deixar claro tal exigência. As outras organizações pesquisadas tendem a verificar esse aspecto na avaliação da proposta. Para elas, esse é o momento de avaliar a possibilidade de repercussão do projeto e a possível visibilidade que o grupo poderá dar à organização. A exigência da divulgação do apoio do financiador parece remeter aos indicadores de eficácia próprios do modelo de sistema aberto. Nesse modelo, segundo Cameron (1978), a avaliação de desempenho da organização está 
focada na aquisição de recursos e de apoio externo. Neste caso, a visibilidade e a repercussão que o grupo teatral poderá dar ao agente financiador do projeto são aspectos de extrema relevância.

Os avaliadores da Brasil Telecom argumentam que o fator mais importante no recebimento da proposta é o conhecimento prévio do trabalho do grupo teatral, que pode acontecer por meio de um relacionamento prévio de confiança e amizade entre o grupo teatral e membros da organização financiadora. O contato pessoal anterior à apresentação da proposta e a assistência a alguma produção teatral do grupo são também pontos positivos para os que pretendem ser financiados.

\section{Avaliação das propostas}

A avaliação do orçamento do projeto cultural ocorre por parte da FCC, da FCFFK, da Brasil Telecom, das Lojas Koerich e do grupo Orcali. Nesse quesito, são analisadas todas as despesas necessárias com transporte, alimentação, figurino e com a produção em geral do espetáculo, bem como dados possíveis de receita oriunda das apresentações a serem realizadas. Esse quesito não é exigido pelo Sesc-SC. A apresentação do orçamento é um critério típico de desempenho vinculado ao modelo de objetivos. Conforme Pace et al (2004), esse modelo está direcionado ao atendimento de metas financeiras. Assim, dados do orçamento do projeto cultural se caracterizam como importantes critérios de avaliação de desempenho organizacional.

De outra perspectiva, indicadores do modelo de objetivos também estão presentes nas avaliações realizadas na FCC, na FCFFK, na Brasil Telecom, no Sesc-SC e no grupo Orcali. Nesse caso, essas organizações avaliam o objetivo do grupo teatral com a apresentação dos espetáculos: se este busca o aprimoramento da platéia através da cultura, se visa ao desenvolvimento dos sentidos (audição ou visão, por exemplo) dessa platéia ou se procura retorno financeiro. Aqui, há uma forte preocupação com os prováveis benefícios da produção para a comunidade, principalmente, por parte da FCC, a FCFFK e o Sesc-SC. No caso do Sesc-SC, após a apresentação teatral é realizada uma atividade chamada "conversando sobre o espetáculo", onde se realiza uma conversa entre o público e o artista para a troca de informações acerca da apresentação. Os entrevistados salientam que essa é uma forma de ampliar a compreensão sobre o espetáculo, é uma forma de educação. De acordo com os entrevistados, a qualidade do projeto também é analisada na FCC, na FCFFK, na Brasil Telecom e no Sesc-SC. Cabe ressaltar que esse tipo de análise da qualidade não é realizado pelas Lojas Koerich nem pela Orcali, que estão mais preocupadas com o custo do projeto e com sua possível repercussão na mídia, em geral, e na comunidade.

Nessa fase de avaliação, tanto na FCC quanto na FCFFK, mais uma vez, também estão presentes indicadores próprios do modelo de processos internos. Nessas organizações, é verificada a viabilidade dos projetos através da análise dos aspectos legais da documentação dos grupos, como o cartão de inscrição no CGC e a certidão negativa de débito com a Fazenda Pública estadual. De acordo com Bowditch e Buono (1992), a eficácia, na perspectiva desse modelo, refere-se à capacidade da organização de estabelecer mecanismos que assegurem estabilidade e controle, por isso a importância atribuída à checagem de documentos

A capacitação dos artistas é um critério analisado pela FCC, pelo Sesc, pelas Lojas Koerich e pelo grupo Orcali, como requisito de competência do grupo. Nesse aspecto, é importante observar a formação de cada um dos integrantes do grupo, bem como suas trajetórias profissionais. No Sesc-SC, a preocupação com a qualificação também é constatada pela atenção dispensada à possibilidade que o projeto apresentado tem de promover o desenvolvimento dos membros do grupo teatral. Para esse financiador, o projeto deve promover a capacitação dos atores, dos diretores e dos demais membros do grupo.

A avaliação das propostas na perspectiva do modelo de sistema aberto também parece estar bastante presente na Brasil Telecom e nas Lojas Koerich, já que a possibilidade de repercussão positiva da imagem das empresas na mídia é enfatizada por essas organizações. A existência de relacionamento prévio de confiança e amizade entre o grupo teatral e membros da organização financiadora são aspectos significativos na obtenção do apoio. Além dessas duas organizações, pode-se perceber a influência dos critérios de eficácia próprios do modelo de 
sistema aberto na FCFFK, porque os grupos teatrais que apresentam em sua proposta uma indicação de contribuinte privado incentivador são analisados de forma diferenciada. Segundo Cameron (1978), uma organização é considerada eficaz na medida em que maximiza sua posição de barganha e otimiza a obtenção de recursos. Muitas vezes, essa posição de barganha pode ser alcançada através de relações sociais (amizade, relações de parentesco ou contatos sociais prévios, por exemplo).

\section{Acompanhamento dos projetos}

A FCC, a FCFFK, a Brasil Telecom e o grupo Orcali avaliam a execução do projeto por meio da prestação de contas financeiras; ou seja, verificam o montante de recursos recolhidos e despendidos, comprovados através de faturas, notas fiscais e recibos, entre outros documentos. Essa exigência tem pressionado os grupos teatrais a estabelecerem mecanismos de controle de documentos, fato que muitas vezes sobrecarrega alguns de seus membros com atividades fora do campo cultural. Esse tipo de avaliação parece remeter ao modelo de processos internos, segundo o qual a eficácia refere-se à capacidade da organização de estabelecer mecanismos que assegurem a estabilidade e o controle, como ocorre quando se dá ênfase à disponibilização de informações por meio de relatórios, formulários e documentos formais dos mais variados tipos.

As exigências de prestação de contas, principalmente, por parte dos agentes financiadores, vêm crescendo rapidamente. Para Silva e Silva (2002, p.1), essa exigência "pode trazer uma mudança profunda no perfil dessas organizações, que de organizações flexíveis, altamente adaptáveis e movidas por ideologias, podem se transformar em organizações altamente burocratizadas e com estrutura rígida".

Nessa etapa de acompanhamento do projeto, parece evidenciar-se também critérios do modelo de sistema aberto na Brasil Telecom, no Sesc-SC e nas Lojas Koerich, pois há preocupação quanto à colocação da marca da empresa nos materiais de divulgação do projeto cultural e acompanhamento da resposta da mídia. Essa orientação para o ambiente é típica desse modelo. Nesse sentido Goulart, Menezes e Gonçalves (2003) afirmam que o setor cultural começa a se beneficiar da importância que as empresas privadas e públicas vêm dando à associação de seus nomes a ações e projetos considerados de importância pela sociedade.

A verificação do atingimento dos objetivos propostos pelo grupo teatral acontece na Brasil Telecom e mais fortemente no Sesc-SC. Na Brasil Telecom, um representante do departamento responsável pelos projetos, normalmente, está presente nas apresentações e mantém contato constante com os produtores e os atores do grupo teatral. O Sesc-SC procura nessa etapa perceber se a qualidade do projeto e sua intenção original estão sendo atingidos. Eles fazem isso com os técnicos que estão nas cidades onde acontecem as apresentações. Utilizando-se de um portal corporativo, os técnicos preenchem um relatório após a realização de cada espetáculo, com informações referentes ao número de pessoas que o assistiram, a resposta da mídia e o relacionamento do grupo com o público, entre outras informações.

\section{Conclusões}

Conforme se argumentou previamente, existem diversas maneiras de mensurar a eficácia, o desempenho ou o sucesso de uma organização. No entanto, Schmid (2002) acredita que em organizações da sociedade civil sem fins lucrativos, considerando a natureza das suas atividades, as quais muitas vezes oferecem serviços intangíveis, é mais difícil de se avaliar e mensurar esse aspecto, principalmente quando comparadas àquelas entidades que visam ao lucro. Ehlers e Calil (2004) argumentam que nessas organizações as dificuldades de monitoramento e de avaliação de suas ações são agravadas devido à natureza qualitativa de seus resultados.

Diversas características relacionadas neste artigo podem ser destacadas como próprias das organizações nesse setor: baixo nível de formalização das atividades e processos, participação dos membros na tomada de decisão, comprometimento dos indivíduos com os objetivos das organizações, objetivos predominantemente de longo prazo e qualitativos (de difícil mensuração), bem como diferentes grupos de interesse a serem atendidos 
(público-alvo, membros internos, Estado e sociedade em geral). Esses aspectos tendem a influenciar, sobremaneira, os critérios mais adequados de avaliação de desempenho a serem utilizados.

Por meio da revisão de literatura realizada, observou-se que nos modelos e indicadores de eficácia utilizados na área organizacional predomina uma discussão ou aplicabilidade de critérios próprios para organizações empresariais. Mesmo nesse contexto, foram constatadas discussões sobre limitações de modelos concentrados em critérios puramente financeiros, de curto prazo, focados em poucos grupos de interesse. Assim, foram observadas propostas que incorporam uma visão de foco interno e externo e de flexibilidade e rigidez, como em Quinn e Cameron (1983) e seu modelo espacial, na colocação de Hall (2004) sobre o modelo de função social e na crítica de Aktouf (1996) quanto à incorporação de variáveis humanísticas radicais na avaliação do desempenho organizacional.

Neste artigo, analisou-se o processo de financiamento de grupos teatrais por seis organizações, de diferentes perspectivas: captação dos projetos, exigências das propostas, avaliação das propostas e acompanhamento dos projetos.

Diante dos dados analisados, identificou-se que as seis organizações estudadas têm uma visão múltipla da avaliação de desempenho, que incorpora uma variedade de critérios. Além disso, os órgãos financiadores da cultura, mais especificamente dos grupos teatrais de Florianópolis, adotam critérios idênticos para analisar organizações culturais com ou sem fins lucrativos.

Dos critérios observados na literatura, aqueles próprios do modelo de recursos humanos estão presentes em praticamente todos os processos de financiamento analisados, com exceção da Brasil Telecom. Dessa forma, critérios como capacitação e currículo dos artistas são considerados relevantes para a análise dos projetos culturais. Isso parece remeter o grupo teatral a uma preocupação constante com a trajetória profissional de seus membros, com as oportunidades de desenvolvimento de que estejam participando.

Parece existir também uma preocupação por parte dos financiadores com questões relativas ao seu ambiente externo. Isso remete tanto a conseqüências no uso de ferramentas de comunicação para o marketing, quanto à construção de sistemas de informação formais e informais. Nessa perspectiva, o modelo de sistemas abertos também foi enfatizado, já que aspectos como repercussão na mídia, benefícios da produção, confiança nos proponentes e publicação dos editais são importantes elementos considerados.

Foi possível observar diversos critérios de avaliação de desempenho que remetem ao modelo de processos internos, tais como a apresentação de diferentes documentos e informações prévias a respeito do grupo teatral e o preenchimento de diferentes formulários. Essa constatação merece reflexão quanto aos impactos dessa exigência, uma vez que diversos autores argumentam que a ênfase em procedimentos internos não seja o foco de organizações civis sem fins lucrativos. A prática da formalização geralmente associada a essas preocupações tem sido muito questionada por membros e estudiosos do setor. Cabe destacar que a ênfase em controles formais, típicos de organizações burocráticas, tem sua aplicabilidade limitada nessas organizações, pois o controle normativo tende a ser muito mais efetivo nesse contexto. Assim, questiona-se qualquer ênfase que agentes financiadores dêem a procedimentos internos na avaliação dessas organizações. Como afirmam Silva e Silva (2002), a conseqüência dessas exigências seria a rigidez na estrutura e, no longo prazo, a ênfase deixar de ser dada aos fins para ser dada aos meios.

A questão dos objetivos é um aspecto fundamental a ser discutido na avaliação dessas organizações. Tema polêmico na área empresarial, não seria diferente em organizações cujos resultados voltam-se para questões de âmbito social. Conforme salientado anteriormente, os objetivos perseguidos por organizações nesse setor concentram-se fundamentalmente em aspectos intangíveis e de longo prazo, tais como ajudar o público a desenvolver sua capacidade intelectual e emocional através do riso, do choro e das emoções, aspectos estes essencialmente diferentes daqueles do campo empresarial, voltados para o retorno financeiro e a maximização do lucro. Conforme afirma Hudson (1999), muitos financiadores estão ávidos por retorno dos recursos investidos nessa área. Assim, visibilidade e publicidade de suas ações têm sido destacadas como importantes 
focos de resultado. No entanto, como bem salienta Montaño (2003), essa visão pode comprometer o rumo das atividades propostas por organizações sociais, levando-as a se preocuparem muito mais em perseguir os objetivos dos financiadores do que atender ao público ou cumprir com a atividade a que sua constituição se propôs. Nesse sentido, argumenta-se que medidas de longo prazo e critérios qualitativos precisam ser incorporados nesse processo de avaliação. As preocupações manifestadas pelo Sesc na avaliação das propostas talvez se aproximem mais dessa concepção de resultado. Nessa organização, há uma preocupação com o conceito, a sinopse e a orientação teórica do projeto e com a linha da proposta artística, visando identificar o possível desenvolvimento cultural do público, não somente com a repercussão na mídia, com a visibilidade dada ao Sesc e com os custos financeiros do projeto.

Coelho (2004) entende que a avaliação por parte dos financiadores de projetos sociais apresenta-se como um tema novo e pouco explorado, sendo considerado um desafio. Ao mesmo tempo em que lidam com lógicas de gestão e avaliação extremamente voltadas para os aspectos econômico-financeiros, devem contemplar critérios substantivos, ou seja,

a análise subsidiada pela avaliação deve contemplar não apenas a utilização eficiente dos recursos, mas se as ações contribuíram para traduzir um impacto social significativo para todos os envolvidos no processo. (Ibidem, p.7)

Ressalta-se aqui que a cultura, como campo de atuação das organizações pesquisadas, é uma dimensão de análise importante a ser considerada. Outros estudos esclarecem que, em diferentes campos de atuação, a avaliação de metas ou resultados pode ser mais ou menos objetivada, dependendo da natureza da atividade desenvolvida. De acordo com Salles e Dellagnelo (2005), por exemplo, no campo das organizações ambientalistas, a dificuldade na avaliação de objetivos parece ser minimizada pela forte vinculação com aspectos técnicos que o desenvolvimento de projetos na área ambiental muitas vezes apresenta. Reis e Santos (1996) discutem pesquisa relativa ao patrocínio de empresas na área artístico cultural, salientando os problemas com os custos elevados, as dificuldades com o planejamento e a visualização de forma de mensuração do retorno.

A reflexão a respeito dos impactos dos indicadores de resultados na constituição de formatos alternativos de organização parece fundamental para estudiosos e gestores de organizações formais. Argumenta-se que, dependendo da direção desses indicadores, o comportamento dessas organizações pode ser diferenciado. Organizações menos formalizadas, mais participativas, efetivamente orientadas para o desenvolvimento pessoal interno e externo e com visão de longo prazo só serão possíveis quando atores fundamentais como os financiadores não estiverem interferindo em direção oposta. As instituições públicas tendem a proporcionar uma influência maior em direção à formalização interna dessas organizações quando enfatizam em seu processo de financiamento elementos próprios de controle internos, de registro de informações. Critérios relativos à qualidade do trabalho artístico parecem ser mais coerentes com a atividade desenvolvida por essas organizações, embora careça de domínio profissional específico e compartilhamento de linguagem própria ao setor por parte dos indivíduos participantes da avaliação de propostas de projetos. Já elementos relativos à visibilidade do projeto cultural podem remeter a conseqüências mais questionáveis às organizações culturais, pois a preocupação com a divulgação de sua imagem e a repercussão do seu trabalho na mídia remete ao desenvolvimento de capacitação profissional em ferramentas de comunicação e marketing, aspectos muitas vezes alheios a essas organizações.

Não se pode negar, conforme afirmam Reis e Santos (1996), que os recursos empresariais poderão ser extremamente impulsionadores de muitas de nossas atividades culturais, mais especificamente quando o Estado diminui sua participação nesse setor. As pesquisas relativas às conseqüências para a dinâmica dessas organizações, no entanto, não podem ser negligenciadas, principalmente, quando se reconhece a intensa discussão na área de estudos organizacionais a respeito de tipos alternativos de organização e gestão 


\section{Referências}

AKTOUF, Omar. À guisa de epílogo: em busca de uma gestão que molda seu desempenho influenciada pela ética e pelo humanismo? In: _. A administração entre a tradição e a renovação. São Paulo: Atlas, 1996.

ANDION, Carolina. Gestão em organizações da economia solidária: contornos de uma problemática. Revista de Administração Pública, Rio de Janeiro, v. 32, n. 1, p. 7-25, jan./fev. 1998.

BARDIN, Laurence. Análise de conteúdo. Lisboa: Edições 70, 2004.

BOWDITCH, J. L; BUONO, A. F. Elementos de comportamento organizacional. São Paulo: Pioneira, 1992.

CAMERON, Kim. Measuring organizational effectiveness in institutions of higher education. Administrative Science Quarterly, v.23, n.4, Dec. 1978.

COELHO, M. Q. Indicadores de performance para projetos sociais: a perspectiva dos stakeholders. In: ENCONTRO NACIONAL DOS PROGRAMAS DE PÓS-GRADUAÇÃO EM ADMINISTRAÇÃO, 28., 2004, Curitiba. Anais... Curitiba: ENANPAD, 2004. 1 CD-ROM.

COULTER, P. B. Organizational effectiveness in the public sector: the example of municipal fire protection. Administrative Science Quarterly, v.24, n.1, Mar. 1979.

CRUZ, M. C. Captação de recursos e contratos. Revista Integração, n.1, set. 1998. Disponivel em: <http://integracao.fgvsp.br>. Acesso em: 22 fev. 2006.

; ESTRAVIZ, M. Captação de diferentes recursos para organizações da sociedade civil. São Paulo: Global, 2000.

DELLAGNELO, E. H. L. Novas formas organizacionais: ruptura com o modelo burocrático? 2000. Tese (Doutorado em Engenharia de Produção e Sistemas) - Programa de Pós-Graduação em Engenharia de Produção e Sistemas, Universidade Federal de Santa Catarina, Florianópolis, 2000.

DELLAGNELO, J. R. G. Modelos de eficácia subjacentes aos programas de remuneração variável. Revista de Negócios, v.2, n.1, out./dez. 1996.

DELLAGNELO, J. R. G. Concepção de eficácia e postura estratégica: um estudo de caso. 1997. Dissertação (Mestrado em Administração) Programa de Pós-Graduação em Administração, Universidade Federal de Santa Catarina, Florianópolis, 1997.

DEMPSEY, S. et al. The use of strategic performance variable as leading indicators in financial analysts' forecasts. Journal of Financial Statement Analysis, New York, v.2, n.4, p.61-80, 1997.

EHLERS, E. M., CALIL, L. P. Monitoramento e avaliação: uma oportunidade de aprendizagem. In: VOLTOLINI, R. (org.) Terceiro setor: planejamento e gestão. São Paulo: SENAC, 2004.

FRASSON, I. Critérios de eficiência, eficácia e efetividade adotados pelos avaliadores de instituições não-governamentais financiadoras de projetos sociais. 2001. Dissertação (Mestrado em Administração)- Programa de Pós-Graduação em Administração, Universidade Federal de Santa Catarina, Florianópolis, 2001.

GOULART, Sueli; MENEZES, Michele Ferreira de; GONÇALVES, Julio César. Composição e características do campo organizacional dos museus e teatros da região metropolitana do Recife. In: CARVALHO, Cristina Amélia, VIEIRA, Marcelo Milano Falcão. Organizações, cultura e desenvolvimento local: a agenda de pesquisa do observatório da realidade organizacional. Recife: EDUFEPE,2003.

HALL, R. H. Organizações: estruturas e processos. Rio de Janeiro: Prentice Hall do Brasil, 2004.

HERMAN, R. D.; RENZ, D. O. Nonprofit organizational effectiveness: contrasts between especially effective and less effective organizations. Nonprofit Management \& Leadership, v.9, n.1, p.23-38, 1998. 
HOFFMANN, S. R. B., DELLAGNELO, E. H. L. Configuração estrutural e objetivos de quatro grupos teatrais de Florianópolis. In: ENCONTRO DE ESTUdOS ORGANIZACIONAIS, 4., 2006, Porto Alegre. Anais... Porto Alegre: EnEO, 2006. 1 CD-ROM.

HUDSON, Mike. Administrando organizações do terceiro setor. São Paulo: Makron Books, 1999.

MONTAÑO, C. Terceiro setor e questão social: crítica ao padrão emergente de intervenção social. 2.ed. São Paulo: Cortez, 2003.

MONTE, T. C, CARVALHO, C. A.. Poder e relações de parceria no terceiro setor. [CD-ROM]. EnEO (Encontro de Estudos Organizacionais), 3. Anais... São Paulo, 2004.

PACE, E. S. U. et al. 0 uso de indicadores de desempenho pelo terceiro setor. In: ENCONTRO DE ESTUDOS ORGANIZACIONAIS, 3., 2004. Anais... São Paulo: EnEO, 2004. 1 CD-ROM.

PERROW, C. The analysis of goals in complex organizations. American Sociological Review, v.26, n.6, p.688-699, Dec. 1961.

QUINN, R. E; CAMERON, K. Organizational life cycles and shifting criteria of effectiveness: some preliminary evidence. Management Science, v.29, n.1, Jan., 1983.

REIS, A. C. F.; SANTOS, R. da C. Patrocínio e mecenato: ferramentas de enorme potencial para as empresas. Revista de Administração de Empresas, v.36, n.2, p.17-25, abr./jun.1996.

ROSSI JÚNIOR, L. R. A gestão para resultados como ferramenta administrativa nas organizações do terceiro setor. Revista Integração, n.2, maio 2001. Disponível em: <http://integracao.fgvsp.br>. Acesso em: 24 mar. 2004.

SALLES, H. K.; DELLAGNELO, E. H. L. A estruturação de organizações ambientalistas do terceiro setor e a relação com o modelo de avaliação de desempenho de suas fontes financiadoras In: ENCONTRO NACIONAL DOS PROGRAMAS DE PÓS-GRADUAÇÃO EM ADMINISTRAÇÃO, 29., 2005, Brasilia. Anais... Curitiba: ENANPAD, 2005. 1 CD-ROM.

SANTOS, R. da C. Reflexões sobre as organizações da sociedade civil. Revista Integração, n.9, dez. 1999. Disponivel em: <http:// integracao.fgvsp.br>. Acesso em: 24 mar. 2004.

SCHMID, Hillel. Relationships between organizational properties and organizational effectiveness in three types of nonprofit human service organizations. Public Personnel Management, Washington, v.31, n.3, p.377-96, fall 2002.

SILVA, G. M.; SILVA, S. G. Relação entre fontes de financiamento e nível de burocratização nas ONGs de Alagoas. In: ENCONTRO DE ESTUDOS ORGANIZACIONAIS , 2., 2002, Recife. Anais... Recife: EnEO, 2002.1 CD-ROM.

SOLĖ, Andreu. ¿Qué es una empresa? Construcción de un ideal tipo transdisciplinario. Paris, 2004. Papel de trabajo.

SZAZI, E. Utilidade pública e OSCIP: como anda a qualificação? Disponível em:<http://www.gife.org.br/artigos_open.php?codigo=6240>. Publicado em 7 jun. 2004. Acesso em: 7 jun. 2004.

YUCHTMAN, E., SEASHORE, S. A system resource approach to organizational effectiveness. American Sociological Review, v.32, n.6, p.891-903, Dec. 1967. 